\title{
Mathematical Modelling Competency for Indonesian Students in Mathematics Education Programmes
}

\author{
Riyan Hidayat' ${ }^{1}$ Zanaton H. Iksan² \\ ${ }^{1}$ Faculty of Education, University Malaya, Kuala Lumpur, Malaysia \\ ${ }^{2}$ Faculty of Education, Universiti Kebangsaan Malaysia, Bangi, Malaysia \\ Email: riyan160989@gmail.com, zanaton.iksan@ukm.edu.my
}

How to cite this paper: Hidayat, R., \& Iksan, Z. H. (2018). Mathematical Modelling Competency for Indonesian Students in Mathematics Education Programmes. Creative Education, 9, 2483-2490. https://doi.org/10.4236/ce.2018.915187

Received: October 2, 2018

Accepted: November 13, 2018

Published: November 16, 2018

Copyright (c) 2018 by authors and Scientific Research Publishing Inc. This work is licensed under the Creative Commons Attribution International License (CC BY 4.0).

http://creativecommons.org/licenses/by/4.0/ (c) (i) Open Access

\begin{abstract}
Previous studies have documented that students have difficulties in mathematical modeling competency. The current research is an attempt to investigate the issue of student's mathematical modeling competency in pre-service mathematics teacher in Indonesia and its analysis in term of Cumulative Grade Points Average (CGPA) gap in Riau Province, Indonesia. The research involved a total of 100 pre-service teacher students in Universitas Islam Riau (UIR). A survey design was employed to investigate the students' mathematical modeling competency using questionnaire of mathematical modeling test. The quantitative data were statistically analyzed using the SPSS 22.0. The descriptive analysis included the percentage, mean and standard deviation while inferential analysis involved Pearson correlation analysis. The results indicated that pre-service mathematics teacher education in Indonesia had moderate level of mathematical modeling competency. However, using graphical representation and interpreting and relating the mathematical solution to the real world context are the most two difficulties in mathematical modeling. At the same time, there was not a significant relationship between CGPA and mathematical modeling competency.
\end{abstract}

\section{Keywords}

Mathematical Modeling Competency, Pre-Service Mathematics Teacher, CGPA

\section{Introduction}

Trend of increased reliance on digital technology influences education and training necessities. How to persuade students in authentic problem solving 
involving complex systems within an interdisciplinary context is the new challenge (English, 2009). It is also necessary to ensure students to keep staying benefit from small group tutoring for related importance of solving complex problems in groups, versus undertaking routine tasks (Reeson, Mason, Sanderson, Bratanova, \& Hajkowicz, 2016; Zakaria, Solfitri, Daud, \& Abidin, 2013). However, since traditional forms of problem solving are seen as independent of the development of core mathematical concepts, understandings, and processes in which students do not have opportunity to investigate complex, messy and real-world data (English, Lesh, \& Fennewald, 2008), application and modelling in mathematics classroom obtain strong support from several educational researcher during the last few decades (Niss, Blum, \& Galbraith, 2007; Yuanita \& Zakaria, 2016) especially using technology (Maat \& Zakaria, 2011).

However, there are a large number of researches reported that students hold difficulties in mathematical modeling competency (Hidayat \& Iksan, 2015; Mentzer, Huffman, \& Thayer, 2014; Yew \& Akmar, 2016). In particular, sub stage of modeling is transitioning from the real world to the mathematical model (Czocher, 2017), which finally causes weak conceptual understanding (Ghazali \& Zakaria, 2011). For example, it is found that the main difficulties encountered by students who deal with word problems concern transforming problems into mathematical models, i.e., in horizontal mathematization while the main barrier concerns horizontal mathematization and formulating mathematical models in particular (Jupri \& Drijvers, 2016). Others also documented that specifically low achievement students might already get stuck in the initial step of the modeling cycle and are unable to get in the step of carrying out mathematical procedures when solving a context-based task (Wijaya, Heuvel-Panhuizen, \& Doorman, 2014). Teachers need to help sufficiently this group of students by understanding their difficulties in mathematics skill required in problem solving. In conclusion, students hold lack of experience related to real-life problem solving.

However, only few literatures have documented the level of mathematical modelling competency in pre-service mathematics teacher education in Indonesia (Hidayat \& Iksan, 2015; Wijaya, Heuvel-Panhuizen, \& Doorman, 2014). With this in mind, this present study is an attempt to investigate the level of mathematical modelling competency in preservice mathematics teacher in Universitas Islam Riau (UIR), Indonesia. The current research will also extend existing mathematical modelling competency literature by discussing mathematical modeling compoetency level of pre-service mathematics teacher education in Indonesia. Therefore, it is aimed in this study at examining the level of mathematical modelling competency in preservice teacher in Indonesia.

\section{Mathematical Modeling Competency}

Modelling competency is closely associated with the definition of the modelling process (Blomhoej \& Jensen, 2003; Blum et al., 2007; Maaß, 2006). However, the mathematical modeling competency in the current research was evaluated 
through eight elements: making simplifying assumptions, clarifying the goal, formulating the problem, assigning variables, parameters and constants, formulating mathematical statements, selecting a model, interpreting graphical representations, and relating back to the real situation (Haines, Crouch, \& Davis, 2000; Haines \& Crouch, 2001) which refer as micro assessment (Houston, 2007).

\section{Methodology}

Survey method was employed to collect students' information in the current research. Participants involved 100 students of a mathematics education program in Riau Province, Indonesia. Female participants were 89 (89\%), whereas male participants were 11 (11\%), with ages ranging from 18 to 22 years old. The gender disproportion in the department of mathematics education program resulted in a large proportion of female participants. The mathematical modelling test was originally developed by Haines and Crouch (2001) and includes the following items: making simplifying assumptions (MMC1), clarifying the goal (MMC2), formulating the problem (MMC3), assigning variables, parameters and constants (MMC4), formulating mathematical statements (MMC5), selecting a model (MMC6), interpreting graphical representations (MMC7), and relating back to the real situation (MMC8). Each correct answer for multiple-choice items was awarded 2 points, and partial credit were awarded 1 point. Wrong answers were awarded 0 points. A total of 22 questions were used in the mathematical modelling test, which had a maximum score of 44 . The reliability value of the mathematical modeling test (0.82) is good (Tavakol \& Dennick, 2011). Hence, in the research, each item of the mathematical modeling competency was retained to examine the mathematical modeling competency of students. A large number of researchers have employed the mathematical modeling instrument with various objectives to measure students' mathematical modeling competency both in secondary and tertiary students (see Frejd \& Ärlebäck, 2011; Fu \& Xie, 2013; Kaiser, 2007; Lingefjärd \& Holmquist, 2005). We use the statistical program SPSS 24.0 for descriptive analysis, Pearson correlation analysis and one-way MANOVA for comparison.

\section{Result}

The mean and standard deviation of the students' total score are summarized in Table 1. The students scored in average 0.89 (SD 0.31), with a minimum scores were 0.00 , meanwhile a maximum scores were 2.00 .

Moreover, Figure 1 indicated the students' score in sub-competency of mathematical modeling.

As seen in Figure 1, the mean values for mathematical modeling competency, which varied among sub-competencies (making simplifying assumptions, $\mathrm{M}=$ 1.12 , clarifying the goal, $\mathrm{M}=0.66$, formulating the problem, $\mathrm{M}=0.68$, assigning variables, parameters and constants, $\mathrm{M}=0.67$, formulating mathematical statements, $\mathrm{M}=0.82$, selecting a model, $\mathrm{M}=0.79$, interpreting graphical 
representations, $M=0.52$, and relating back to the real situation, $M=0.57)$. In addition, Table 2 showed that there was not a significant relationship between CGPA and mathematical modeling competency $r=0.083$ and sig. $=0.409(p>$ $0.01)$.

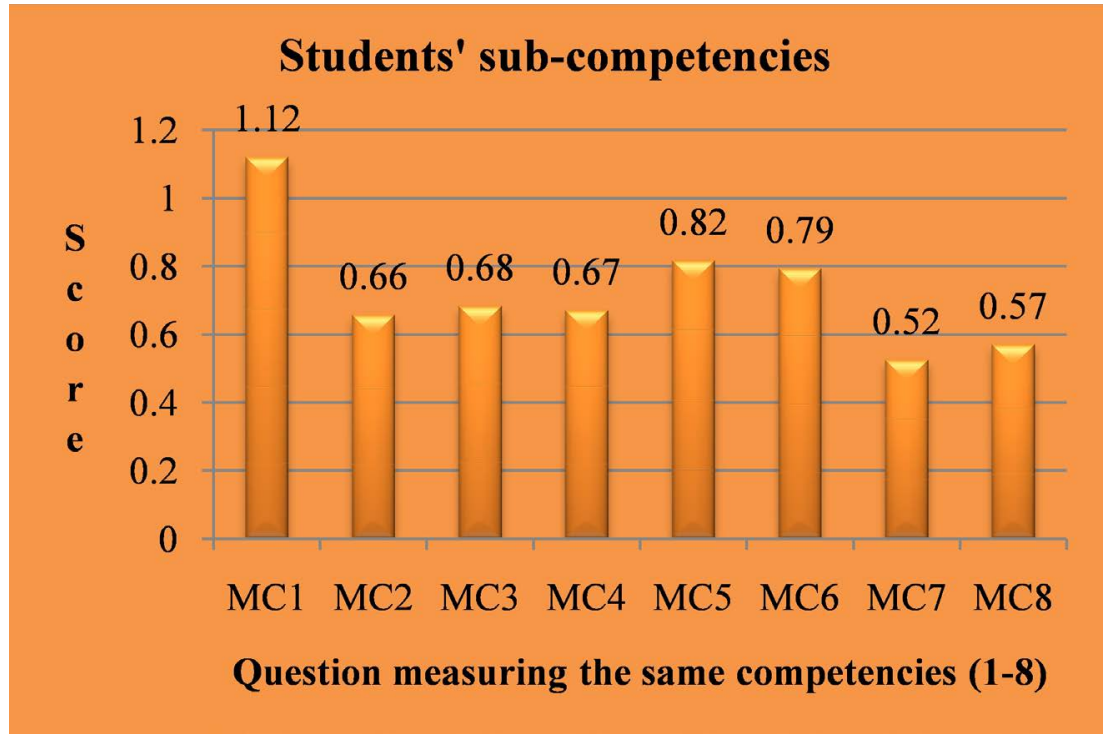

Figure 1 Students' sub-competencies.

Table 1. Means and standard deviations of scores on the mathematical modeling competency.

\begin{tabular}{cc}
\hline Results & \\
Mean & 0.89 \\
Std. Deviation & 0.31 \\
Minimum & 0.00 \\
Maximum & 2.00
\end{tabular}

Table 2. Pearson correlation between CGPA and mathematical modeling competency.

\begin{tabular}{cccc}
\hline & CGPA & $\begin{array}{c}\text { Mathematical } \\
\text { Modeling Competency }\end{array}$ \\
& Pearson Correlation & 1 & 0.083 \\
CGPA & Sig. (2-tailed) & & 0.409 \\
& $\mathrm{~N}$ & 100 & 100 \\
$\begin{array}{c}\text { Mathematical } \\
\text { Modeling }\end{array}$ & Pearson Correlation & 0.083 & 1 \\
Competency & Sig. (2-tailed) & 0.409 & 100 \\
\hline
\end{tabular}




\section{Discussion}

In the current research, comparing the sub-competencies of mathematical modeling competency in pre-service mathematics teacher in Indonesia, the results indicated that pre-service mathematics teacher education in Indonesia had moderate level of mathematical modeling competency. Figure 1 revealed that they were most competent in questions relating to making simplifying assumptions and formulating mathematical statements, but exhibited more difficulties in questions relating to interpreting graphical representations, and relating back to the real situation. We identified the difficulties that students encountered in the process of mathematical modelling competency, which will assist the teacher to improve by selecting the most appropriate strategy (Haines \& Crouch, 2013). For the sub-competence of MMC7, this finding coincides with the findings of the studies performed by Frejd and Ärlebäck (2011), and Kaiser (2007). However, our research was not in line with Frejd \& Ärlebäck's (2011) findings in which they reported that making simplifying assumptions and formulating mathematical statements were more difficult for secondary school student. We found that this competency was most proficient for tertiary level students. One of possible reasons, for example, is that students in undergraduate level had a strong mathematics background so they had adequate knowledge of mathematical lessons easily in term of formulating mathematical statements. Another explanation of this result might be closely associated with experience in mathemtical modeling competency such as the students' last-taken mathematics course (Frejd \& Ärlebäck, 2011).

Relationship between Cumulative Grade Points Average (CGPA) and mathematical modelling competency in the current research was not significant, based on Pearson correlation analysis. The results obtained in this small-survey study did resonate with the findings reported in the large body of empirical studies that indicate student who is successful in conventional standardized mathematics assessments cannot predict the success in mathematical modeling task (Fu \& Xie, 2013). The possible reason why this happens is not very clear and requires further examination and discussion using a more sophisticated statistical analysis.

\section{Conclusion and Suggestion}

The findings of present research provide further evidence that mathematical modeling competency for Indonesian students in mathematics education programmes had moderate level of mathematical modeling competency. Nonetheless, using graphical representation and interpreting and relating the mathematical solution to the real world context are the most two difficulties in mathematical modeling. No significant difference is observed between male and female students in all mathematical modeling competency sub-constructs. Moreover, there was not a significant relationship between CGPA and mathematical modeling competency. One of the practical implications is that teachers can present a 
suitable learning strategy to enhance the mathematical modeling competency. The finding of the current research will also contribute to the Ministry of Education in Indonesia with current data that would aid the ministry in making better policy decisions and applying educational strategies with greater certainty for the implementation of curriculum in University. Our research has some limitations. First, the definition of mathematical modeling competency employed in this study is slightly restricted. The current research involves mathematical modeling competency in a content perspective. Mathematical modeling competency in modeling as a vehicle should be analyzed. Hence, an experimental study involving mathematical modeling competency as a vehicle should be conducted.

\section{Conflicts of Interest}

The authors declare no conflicts of interest regarding the publication of this paper.

\section{References}

Blomhoej, M., \& Jensen, T. (2003). Developing Mathematical Modelling Competence: Conceptual Clarification and Educational Planning. Teaching Mathematics and Its Applications, 22, 123-139. https://doi.org/10.1093/teamat/22.3.123

Blum, W., Galbraith, P. L., Henn, H.-W., \& Niss, M. (2007). Modelling and Applications in Mathematics Education: The 14 ICMI Study. Zhurnal Eksperimental'noi i Teoreticheskoi Fiziki (Vol. 10). Boston, MA: Springer Science + Business Media. https://doi.org/10.1007/978-0-387-29822-1

Czocher, J. A. (2017). Mathematical Modeling Cycles as a Task Design Heuristic. The Mathematics Enthusiast, 14, 129-140. http://scholarworks.umt.edu/tme/vol14/iss1/9

English, L. D. (2009). Promoting Interdisciplinarity through Mathematical Modelling. ZDM Mathematics Education, 41, 161-181. https://doi.org/10.1007/s11858-008-0106-Z

English, L., Lesh, R., \& Fennewald, T. (2008). Future Directions and Perspectives for Problem Solving Research and Curriculum Development. In 11th International Congress on Mathematical Education (pp. 6-13). Monterrey, Mexico: Unpublished.

Frejd, P., \& Ärlebäck, J. B. (2011). First Results from a Study Investigating Swedish Upper Secondary Students' Mathematical Modelling Competencies. In G. Kaiser, W. Blum, R. Borromeo, \& G. Stillman (Eds.), Trends in Teaching and Learning of Mathematical Modelling. International Perspectives on the Teaching and Learning of Mathematical Modelling (Vol. 1, pp. 407-416). Dordrecht: Springer.

https://doi.org/10.1007/978-94-007-0910-2_40

Fu, J., \& Xie, J. (2013). Comparison of Mathematical Modelling Skills of Secondary and Tertiary Students. In G. A. Stillman, W. Blum, G. Kaiser, \& J. P. Brown (Eds.), Teaching Mathematical Modelling: Connecting to Research and Practice (pp. 165-173). New York \& London: Springer Dordrecht Heidelberg. https://doi.org/10.1007/978-94-007-6540-5_14

Ghazali, N. H. C., \& Zakaria, E. (2011). Students' Procedural and Conceptual Understanding of Mathematics. Australian Journal of Basic and Applied Sciences, 5, 684-691.

Haines, C., \& Crouch, R. (2001). Recognizing Constructs within Mathematical Modelling. Teaching Mathematics and Its Applications, 20, 129-138. 
https://doi.org/10.1093/teamat/20.3.129

Haines, C., Crouch, R., \& Davis, J. (2000). Mathematical Modelling Skills: A Research Instrument.

Haines, C. R., \& Crouch, R. (2013). Remarks on a Modeling Cycle and Interpreting Behaviours. In R. Lesh, C. R. Haines, P. L. Galbraith, \& A. Hurford (Eds.), Modeling Students' Mathematical Modeling Competencies, International Perspectives on the Teaching and Learning of Mathematical Modelling (pp. 145-154). London and New York: Springer. https://doi.org/10.1007/978-94-007-6271-8_12

Hidayat, R., \& Iksan, Z. H. (2015). The Effect of Realistic Mathematic Education on Students' Conceptual Understanding of Linear Progamming. Creative Education, 6, 2438-2445. https://doi.org/10.4236/ce.2015.622251

Houston, K. (2007). Assessing the "Phases" of Mathematical Modelling. In W. Blum, H.-W. Henn, P. L. Galbraith, \& M. Niss (Eds.), Modelling and Applications in Mathematics Education: The 14th ICMI Study(Vol. 10, pp. 249-255). New York: Springer. https://doi.org/10.1007/978-0-387-29822-1_26

Jupri, A., \& Drijvers, P. (2016). Student Difficulties in Mathematizing Word Problems in Algebra. Eurasia Journal of Mathematics, Science \& Technology Education, 12, 2481-2502. https://doi.org/10.12973/eurasia.2016.1299a

Kaiser, G. (2007). Modelling and Modelling Competencies in School. In C. Haines, P. Galbraith, W. Blum, \& S. Khan (Eds.), Mathematical Modelling ICTMA 12: Education, Engineering and Economics (pp. 110-119). Chichester: Horwood. https://doi.org/10.1533/9780857099419.3.110

Lingefjärd, T., \& Holmquist, M. (2005). To Assess Students' Attitudes, Skills and Competencies in Mathematical Modeling. Teaching Mathematics and Its Applications, 24, 123-133. https://doi.org/10.1093/teamat/hri021

Maat, S. T., \& Zakaria, E. (2011). Exploring Students' Understanding of Ordinary Differential Equations Using Computer Algebraic System (CAS). The Turkish Online Journal of Educational Technology, 10, 123-128.

Maaß, K. (2006). What Are Modelling Competencies? ZDM, 38, 113-142. https://doi.org/10.1007/BF02655885

Mentzer, N., Huffman, T., \& Thayer, H. (2014). High School Student Modeling in the Engineering Design Process. International Journal of Technology and Design Education, 24, 293-316. https://doi.org/10.1007/s10798-013-9260-x

Niss, M., Blum, W., \& Galbraith, P. (2007). Introduction. In W. Blum, P. L. Galbraith, H.-W. Henn, \& M. Niss (Eds.), Modelling and Applications in Mathematics Education (10th ed., pp. 2-32). New York, NY: Springer. https://doi.org/10.1007/978-0-387-29822-1_1

Reeson, A., Mason, C., Sanderson, T., Bratanova, A., \& Hajkowicz, S. (2016). The VET Era Equipping Australia's Workforce for the Future Digital Economy. Queensland.

Tavakol, M., \& Dennick, R. (2011). Making Sense of Cronbach's Alpha. International Journal of Medical Education, 2, 53-55. https://doi.org/10.5116/ijme.4dfb.8dfd

Wijaya, A., Van Den Heuvel-panhuizen, M., \& Doorman, M. (2014). Difficulties in Solving Context-Based PISA Mathematics Tasks: An Analysis of Students' Errors. The Mathematics Enthusiast, 11, 555-584.

Yew, W. T., \& Akmar, S. N. (2016). Problem Solving Strategies of Selected Pre-Service Secondary School Mathematics Teachers in Malaysia. The Malaysian Online Journal of Educational Sciences, 4, 17-31.

Yuanita, P., \& Zakaria, E. (2016). The Effect of Realistic Mathematics Education (RME) 
Implementation to Mathematics Belief, Mathematics Representative and Mathematics Problem Solving. Advanced Science Letters, 22, 1989-1992.

https://doi.org/10.1166/asl.2016.7754

Zakaria, E., Solfitri, T., Daud, Y., \& Abidin, Z. (2013). Effect of Cooperative Learning on Secondary School Students' Mathematics Achievement. Creative Education, 4, 98-100. https://doi.org/10.4236/ce.2013.42014 